Preprint, for presentation at the 219th ACS National Meeting to be held in San Francisco, CA on March 26-30, 2000.

\title{
SMALL ANGLE X-RAY SCATTERING STUDY OF COAL SOOT FORMATION*
}

\author{
R. E. Winans, J. T. Parker ${ }^{\dagger}$, S. Seifert, and T. H. Fletcher ${ }^{\dagger}$
}

\author{
Chemistry Division \\ Argonne National Laboratory
}

Argonne, IL 60439

and

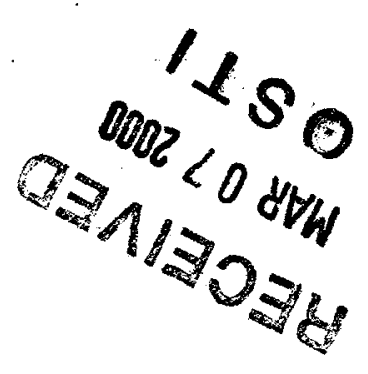

${ }^{\dagger}$ Chemical Engineering Department

Brigham Young University

Provo, UT 84602

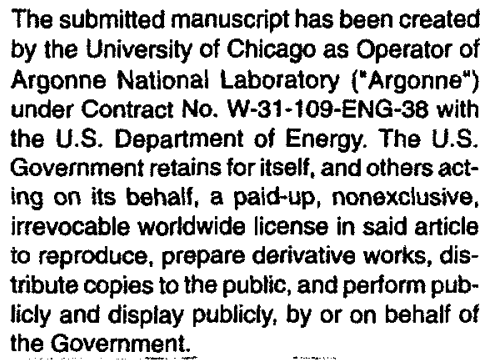

*This work was performed under the auspices of the Office of Basic Energy Sciences, Division of Chemical Sciences, U.S. Department of Energy, and use of the Advanced Photon Source was supported by BES-DOE, all under contract number W-31-109ENG-38. 


\section{DISCLAIMER}

This report was prepared as an account of work sponsored by an agency of the United States Government. Neither the United States Government nor any agency thereof, nor any of their employees, make any warranty, express or implied, or assumes any legal liability or responsibility for the accuracy, completeness, or usefulness of any information, apparatus, product, or process disclosed, or represents that its use would not infringe privately owned rights. Reference herein to any specific commercial product, process, or service by trade name, trademark, manufacturer, or otherwise does not necessarily constitute or imply its endorsement, recommendation, or favoring by the United States Government or any agency thereof. The views and opinions of authors expressed herein do not necessarily state or reflect those of the United States Government or any agency thereof. 


\section{DISCLAIMER}

Portions of this document may be illegible in electronic image products. Images are produced from the best available original document. 


\section{Chemistry Division, Argonne National Laboratory, Argonne, IL 60439} and ${ }^{\dagger}$ Chemical Engineering Department, Brigham Young University, Provo, UT 84602

\section{Keywords:}

\section{ABSTRACT}

The objective of this study is to examine, by small angle X-ray scattering (SAXS), the formation of soot from individual coal particle combustion in a methane flat flame burner. The SAXS instrument at the Basic Energy Sciences Synchrotron Radiation Center (BESSRC) at the Advanced Photon Source (APS) can be used to observe both the formation of spherules and clusters since it can access length scales of 6-6000 $\AA$. The high X-ray flux enables rapid acquisition of scattering data of various regions of the flame. SAXS data reveal particle size, shape, surface areas, and surface roughness.

\section{INTRODUCTION}

Particulate formation in many types of combustion, such as in diesel engines and coal combustion, is a significant problem. For example, in coal combustion, soot formation control is important because of radiation heat transfer effects. The objective of this study is to observe in situ the formation of particles in flames using small angle X-ray scattering (SAXS). As a result of a DOEBES Facilities Initiative (1), we have developed a high resolution SAXS instrument in the BESSRCCAT at the Advanced Photon Source (APS). The SAXS facility offers new capabilities for measuring atomic order within disordered media, including combustion particulates, on a length scale of 6-6000 A. A small research, flat flame burner has been constructed. The flux of photons from an undulator at the APS is needed to be able to observe the small number of soot particles in combustion of single coal particles.

We propose to look at the problem of particulate formation in coal combustion from the early growth stages to particulate agglomerate formation, all using SAXS. In an early in situ study (3) using SAXS to probe flames, the author noted that optical techniques had a lower limit of $600 \AA$ while his instrument had an upper limit of $1000 \AA$. Typically, individual soot particles cluster to sizes starting at $\sim 1000 \AA$. Optical methods can readily observe the clusters, but not the smaller spherules as they are formed. Our instrument can observe both the formation of spherules and clusters since it can access length scales of 6-6000 $\AA$. SAXS data can reveal particle size, shape, surface areas, surface roughness and can provide information on the internal structure. This method provides complementary data to that obtained by optical methods.

Presently, a number of optical techniques are used to study soot in flames. Recently, Köylü (4) observed that there were large errors in determining soot particle size from light scattering. Also, the determination of properties were suspect due to uncertainties in soot refractive indices. However, thermophoretic sampling compiled with transmission electron spectroscopy (an ex situ method) has provided reliable size and shape information on the soot aggregates $(4,5)$. These data can be used to help interpret the in situ SAXS results. Other optical techniques, such as laser induced fluorescence (6), have been used to analyze the pyrolysis process and especially to look at the polycyclic aromatic hydrocarbons, which are the probable precursors to soot.

A classic paper by Freltoft, Kjems, and Sinha (7) describes how power law correlations of small angle scattering can be used to describe clusters of small particles. A parameter called the fractal dimension $\left(d_{0}\right)$ can be derived from this correlation. This value, $d_{o}$, relates how the mass of a cluster changes with a linear dimension. We have used this approach to examine coal derived molecules in pyridine with small angle neutron scattering data (8).

The experiments were conducted using a smaller version of a Hencken flat flame burner using a methane-air flame as the heat source. The coal particles are introduced individually through the center of the burner (5). It can be run fuel rich to observe pyrolysis or fuel lean to combust the coal particles. Other fuels, such as hydrocarbons, have been used with this burner. The burner is mounted on vertical and horizontal translation stages so that different parts of the flame can be probed. 


\section{EXPERIMENTAL}

The SAXS instrument was constructed at ANL and used on the Basic Energy Sciences Synchrotron Radiation Center CAT undulator beamline ID-12 at the Advanced Photon Source (http://www.bessrc.aps.anl/). The SAXS instrument has been designed to minimize parasitic scattering which would interfere with scattering from dilute samples such as soots in flames. An important key to this feature of the instrument is that the beam is defined $20 \mathrm{~m}$ from the sample which reduces the problem of scattering from the defining slits. A schematic of the instrument is shown in Scheme 1.

Monochromatic X-rays $(8.5-23.0 \mathrm{keV})$ are scattered off the sample and collected on a 9-element mosaic CCD detector $(15 \times 15 \mathrm{~cm})$ with maximum of $3000 \times 3000$ pixel resolution with $10 \mathrm{sec}$ exposure times. ${ }^{9}$ The scattered intensity has been corrected for absorption, the air scattering, and instrument background. The differential scattering cross section has been expressed as a function of the scattering vector $Q$, which is defined as $Q=(4 \pi / \lambda) \sin \theta$, where $\lambda$ is the wavelength of the $\mathrm{X}$-rays and $\theta$ is the scattering half angle. The value of $\mathrm{Q}$ is proportional to the inverse of the length scale $\left(\AA^{-1}\right)$. The instrument was operated with two different sample-to-detector distances, $68.5 \mathrm{~cm}$ to obtain data at $0.04<\mathrm{Q}<0.7 \AA^{-1}$ and $3740 \mathrm{~cm}$ to measure at $0.006<\mathrm{Q}<0.1 \AA^{-1}$.

The Argonne Premium Coal Samples ${ }^{10}$ used in this study were sized to the range of $45-75 \mu \mathrm{m}$. The burner used for these studies was a 1" x 1" axial symmetric flat flame burner produced by Research Technologies. The coal and liquids were fed through a tube centered in the burner and, a 0.25 " nitrogen and helium co-flow around the perimeter was used to stabilize the methane/hydrogen flame. The individual coal particles were fed to the flame using a technique which that has previously been described. ${ }^{5}$ Liquid samples were introduced into the flame via a $0.25 \mu \mathrm{m}$ fused silica tube which protruded $2 \mathrm{~mm}$ above the surface of the burner. Samples such as toluene and heptane were flowed into the flame at $0.1 \mathrm{ml}$ using an automated syringe.

The burner was mounted on a $x-y$ translational stage such that the flame could be moved through the $\mathrm{X}$-ray beam both vertically and horizontally.

\section{Small Angle X-ray Scattering}

A typical plot of the scattering data for soot formation as a function of distance from the top of the burner of the Illinois No. 6 bituminous coal (APCS 3) is shown in Figure 1. These curves can be analyzed to determine size of features, topology, and changes in total scattering. Power law slope from the data, such as is shown in Figure 1, are used to describe the topology of the system. Finally, the invariant $\mathrm{Q}_{0}$ is calculated and is proportional to the fluctuation of the electron density in the system. Changes in the invariant are useful in monitoring topological changes in the sample, $Q_{0}=\int_{0}^{\infty} I(Q) Q^{2} d Q$. For example, the invariant goes to zero for a homogeneous system that does not have any concentration fluctuation.

\section{RESULTS AND DISCUSSION}

The scattering data were obtained as the burner was moved in $1 \mathrm{~mm}$ steps, such that the X-ray beam passed through the flame vertically from the bottom $(0 \mathrm{~mm})$ to $40 \mathrm{~mm}$ above the bottom. In addition, vertical sets of data were collected as the beam was positioned on center, where the coal particles emerged, and $1 \mathrm{ml}$ increments from the center. The Illinois No. 6 (APCS 3) data from a vertical set at the center of the burner is shown in Figure 1. An initial Guinier analysis of this data suggests that the particle sizes are polydispersed over the section of the flame where soot is observed. Also, there are no systematic changes in the invariant. However, as can be seen in Figure 2, the power law slope is increasing. This suggests that there is a roughening in the soot particle surface. Note the large amount of scatter in the data. This may mean that a wide range of soot particles are observed, or else that there is merely a lot of scatter in the data. With combustion of the coal particles, the scattering decreased rapidly as the X-ray beam is moved away from the center (not shown)and becomes difficult to measure at $3 \mathrm{~mm}$ from the center.

Hydrocarbons, such as toluene, gave much better data in this system than coal particles. The flame conditions and the data acquisition parameters are the same in both cases, but apparently a much more stable soot cloud results from the direct infusion of the aromatic hydrocarbon. The power law slope data for the toluene $(Q=0.016$ to 0.04$)$ is shown in Figure 3. For the first $5-10 \mathrm{~mm}$ of the lower part of the flame, the value of $d_{o}=2.0$, strongly suggests that larger polycyclic aromatic 
molecules or small clusters are being observed. For layered materials such as graphite, $d_{o}=2.0$, while for disordered carbons $d_{o}>3.0$, which is observed at longer distances from the top of the burner. As expected, the scattering for the combustion of heptane (not shown) was much less than that for toluene.

\section{CONCLUSIONS}

Some of the initial results look promising, but we need a low flame temperature in order to observe the intermediate sized particles. This approach may reduce the polydispersity.

\section{ACKNOWLEDGMENTS}

This work was performed under the auspices of the Office of Basic Energy Sciences, Division of Chemical Sciences, U.S. Department of Energy, and use of the Advanced Photon Source was supported by BES-DOE, all under contract number W-31-109-ENG-38. The support of the BESSRC staff is appreciated, especially J. Linton, M. Beno, G. Jennings, and M. Engbretson.

\section{REFERENCES}

1. DOE-BES Facilities Initiative entitled "Development of a Facility at APS for TimeResolved/Anomalous Small Angle X-ray Scattering: Applications in Condensed Matter Research," R. E. Winans, P. Thiyagarajan, R. K. Crawford, K. A. Carrado, and D. M. Tiede.

2. McLean, W. M.; Hardesty, D. R.; and Poll, J. H. Proc., $18^{\text {th }}$ Symp. (Int'l.) Combust., 1213 (1980).

3. England, W. A. Combust. Sci. and Tech. 1986, 46, 83-93.

4. Köylü, Ü. Ö. Combustion and Flame 1996, 109, 488-500.

5. Ma, J.; Fletcher, T. H.; Webb, B. W. Energy Fuels 1995, 9, 802-808.

6. Ragucci, R.; De Joannon, M.; Cavaliere, A. Proc., $26^{\text {th }}$ Symp. (Int'l.) Combust., Vol. 2, 2525-2531 (1996).

7. T. Freltoft, J. K. Kjems, S. K. Sinha, Phys. Rev. B. 33, 269-275 (1986).

8. Cody, G. D.; Thiyagarajan, P.; Botto, R. E.; Hunt, J. E.; Winans, R. E. Energy Fuels 1994, 8, 1370-1378 (1994).

9. . Westbrook, E. M.; Naday, I. Methods Enzymol. 1997, 276, 244-268.

10. Vorres, K. S. Energy Fuels 1990, 4, 420-426.

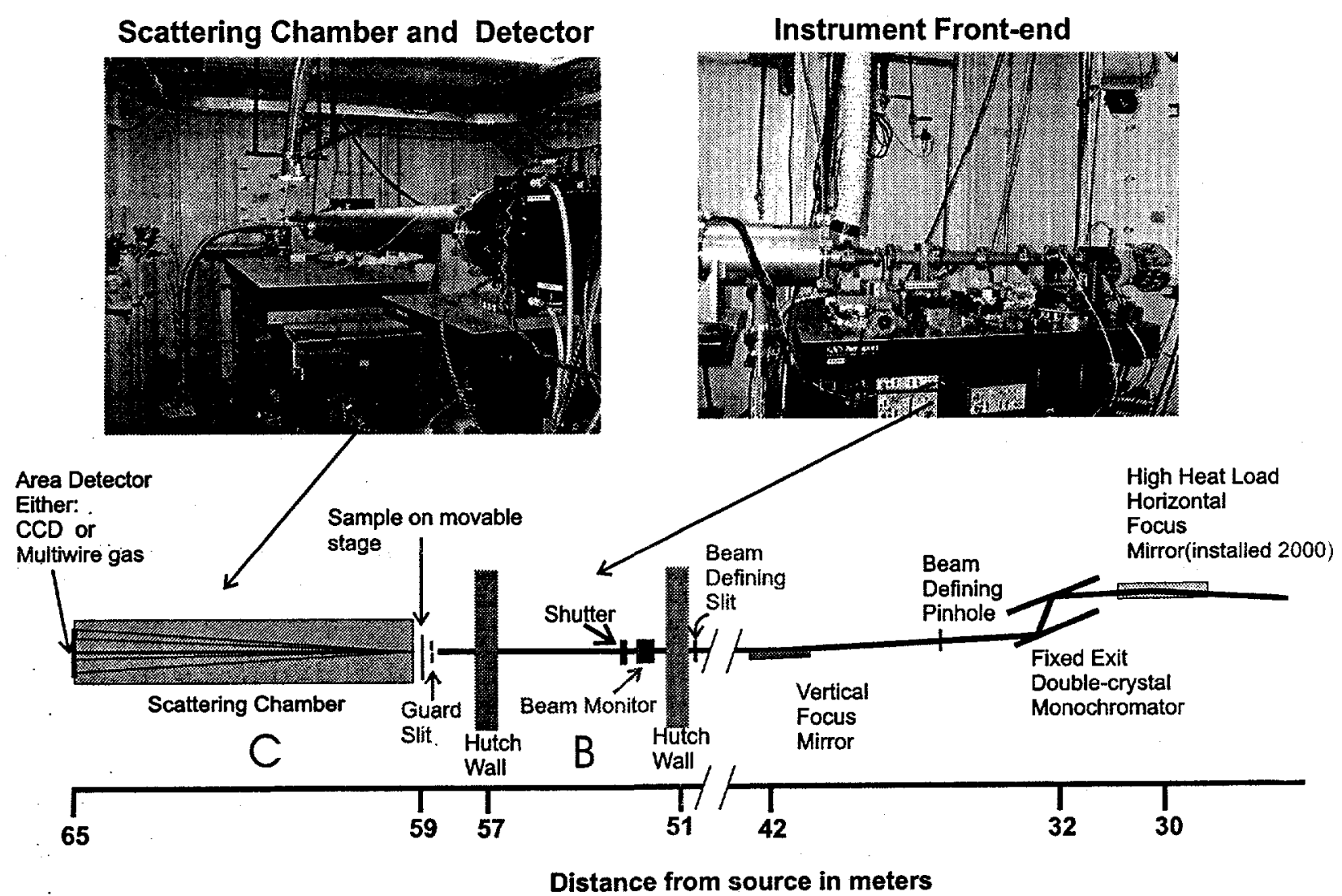

Scheme 1. TR/ASAXS Instrument on the APS BESSRC ID-12-B\&C Undulator Beamline 


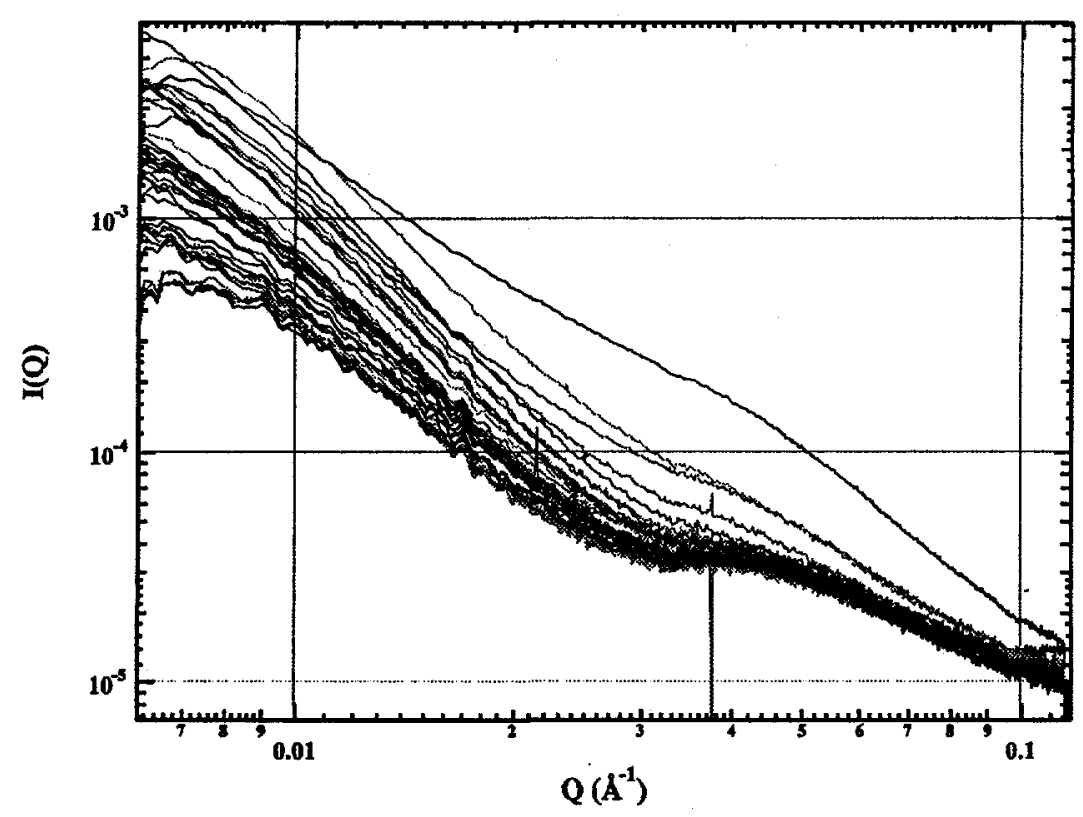

Figure 1. Scattering from Illinois coal (APCS 3) taken at $1 \mathrm{~mm}$ intervals from 0 to $40 \mathrm{~mm}$ above the top of the burner centered.

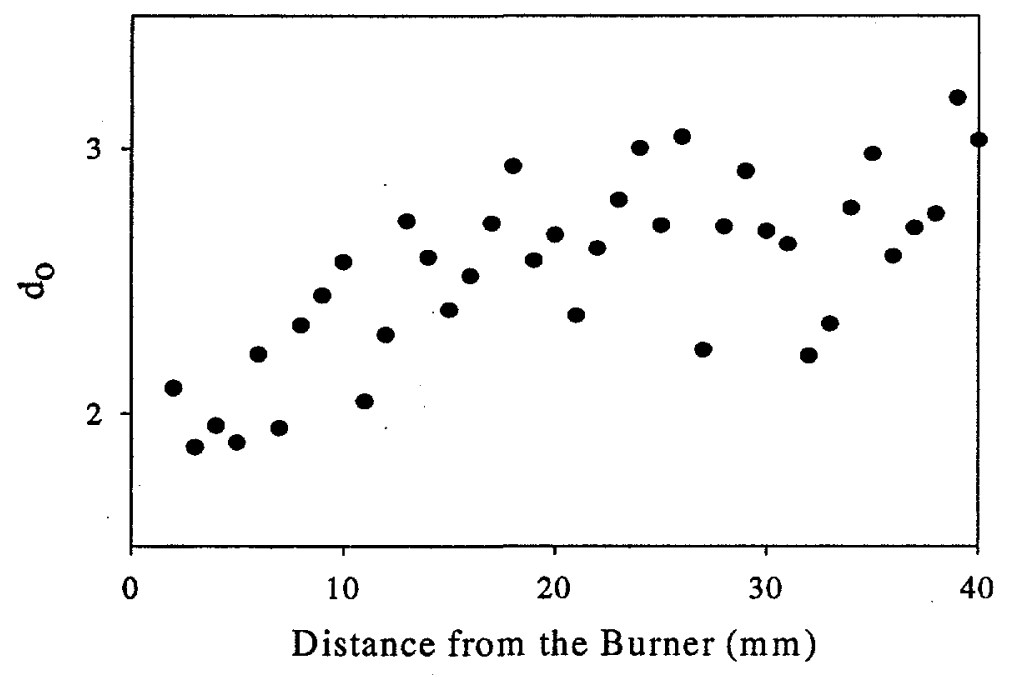

Figure 2. Power law slope from scattering of Illinois coal (APCS 3) soot taken along the centerline at $1 \mathrm{~mm}$ intervals from 0 to $40 \mathrm{~mm}$ above the top of the burner.

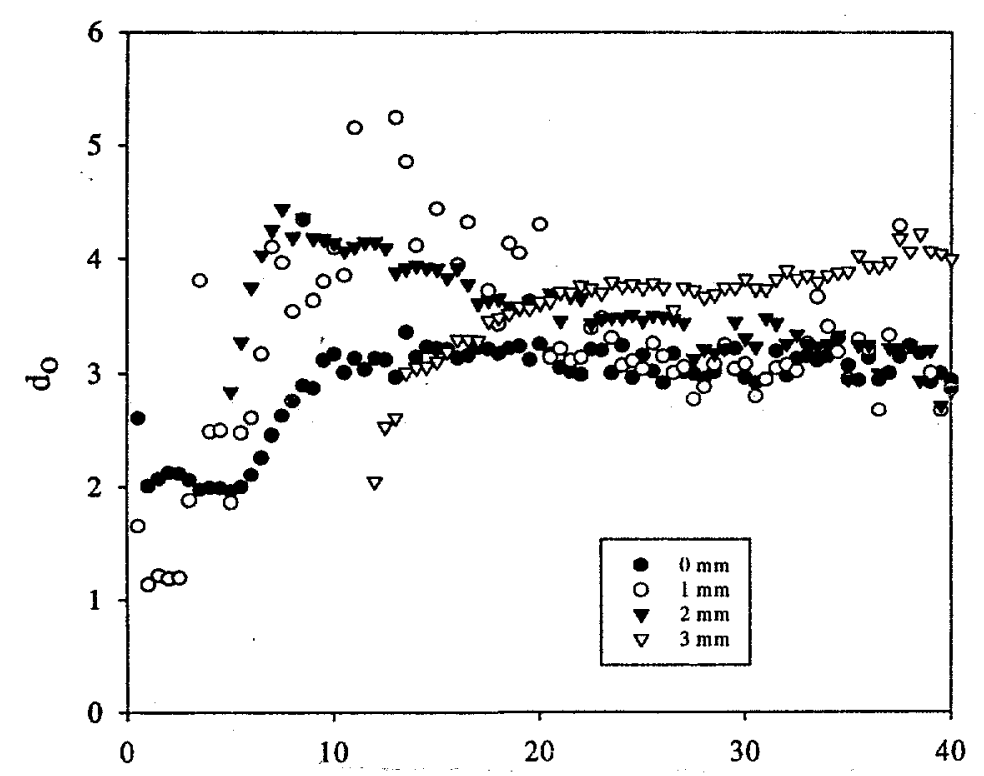

Figure 3. Power law slope from scattering of toluene soot taken at $1 \mathrm{~mm}$ intervals from 0 to 40 $\mathrm{mm}$ above the top of the burner at $1 \mathrm{~mm}$ intervals from the center. 